\title{
Energy Efficiency Feasibility Study of a Novel Buoyancy Driven Hydropower Generation Machine
}

\author{
A. Shokohi and A. Kiyoumarsioskouei
}

\begin{abstract}
Utilization of the different mechanism to earn river's hydropower had been a long-term target for human beings. One of the new methods for achieving this end is reciprocating buoyancy driven mechanism which contains three Vertical cylinders with a light piston in the central cylinder. Fluid is being led to downstream of the system from one of the cylinders by opening the discharge valve of the aforementioned cylinder; water pressure exerts force on the piston which is located in the other parallel cylinder and consequently the piston moves, this would basically be the power generation cycle. In the next step discharge valve of the second cylinder is opened and leads the water to the drainage. This step simply facilitates the piston's return to the initial position. Calculating the head loss occurring inside the cylinders and the other losses results the efficiency estimation more than 90 percent that could be improved easily by optimizing the design and also using better quality materials in the manufacturing process of the machine. This could be an appropriate achievement for regenerative energy production enhancement in the world.
\end{abstract}

Index Terms-Clean energy, hydropower, reciprocating mechanism, head loss.

\section{INTRODUCTION}

There is an ever increasing demand for energy in the world. The main resource of energy has been the fossil fuels, which have been used to generate electricity and it is the most convenient and desired type of energy [1]. However, due to the problems with burning fossil fuels such as pollution, greenhouse effect, and the limited resources, there is a crucial need for other energy resources [1]. Many researchers throughout the world have dedicated their time and research facilities to find new ways of harnessing energy from renewable sources but the progress and achievements has not been satisfactory yet.

Human beings had been always relying on hydrocarbon-based fuels. Arboreal fuels such as woods and coal have been utilized as long as mankind knows about fire. About two centuries ago, we started extracting energy from fossil fuels. However, there are some serious concerns with them. Namely, the changes occurred to environmental conditions of the earth due to oil and gas production, transportation and consumption. Air pollution in cities and industrial parks as well as the greenhouse effect are the most tangible detriments that come with burning the fossil fuels [2].

Manuscript received December 30, 2013; revised March 24, 2014

A. shokuhi is with the Tehran's YASHIL Renewable Energy Research Center, Iran (e-mail: alishokohiniaki@gmail.com).

A. Kiyoumarsioskouei was with Amir Kabir University, Tehran, Iran. He is now with the Tehran's YASHIL Renewable Energy Research Center, Iran (e-mail: kiumarsi@mech.sharif.edu).
Moreover, population growth and emergence of new industries have rendered an increasing energy demand in the world in the past decades. Thus, it is needless to say that we cannot depend only on fossil fuels. Many researchers throughout world started to work on new ways to provide the required energy for continuing life on earth. Nuclear energy, solar energy, wind energy, and many other energy sources have been employed in order to generate electricity which is the most convenient form of energy to be used by both household and industrial energy consumers [3]. However, there have been some serious flaws as the demand for oil and gas is still increasing.

Renewable sources of energy are the most promising candidates to be considered as the energy resources for future life on earth [3]. As mentioned before, there have been some efforts to find efficient ways for extracting energy in solar radiations and wind currents. However, the electricity generated from these resources is not economic. Because, the approaches applied in solar cells and wind turbines are not satisfactorily efficient and also the equipment used in these types of power plants are highly intricate and expensive [3]. Using biomass is another source of energy to generate power, but the source of this energy is not as widespread as wind or solar energy.

Another energy resource that could be a significant energy resource is the mechanical energy potential in natural water currents (especially in the sub-regions close to the seas) [4]. Human beings have been extracting electricity by storing water behind dams and running water turbines. There are several difficulties and also environmental issues with building dams and storing water in artificial lakes. By utilizing the energy of water as it is flowing down in rivers there is no need to establish dams and store water behind it. This will eliminate lots of environmental effects and expenses that dams have and lots of other problems which dams facing with i.e. water waste due to evaporation.

\section{Procedure And Physics of The Machine}

Before explaining the work of this project it would be helpful to define some technical terms and mechanical rules that are going to be referred in future arguments. The following list of terms is defined and described in the current section.

Total energy of fluid: Total energy of fluid is the sum of three terms; Potential energy that it has because of its elevation from earth surface, kinetic energy that the fluid acquires as it starts to flow in a direction, and the energy it has because of its pressure. Total energy of fluid will not remain constant as it flows because of the energy dissipated by shear 
stress between the fluid and it adjacent walls [5].

Buoyancy force: As it is popular in science the net force acted on body submerged in fluid is the summation of weight and Archimedes force. This net force may be downward, upward, or zero regarding to a magnitude of $r$ which is a dimensionless parameter defining the ratio of body density to its outer-fluid density. If $r>1$ then force is downward, $r=1$, the force is zero, and as when the " $r$ " is less than unity the force will be upward. In This work the buoyancy force appears as the pressure difference between two sides of the piston which is the most important factor of movement creation [5].

The mechanism described in this report is a system that extracts mechanical energy of the water flows in the rivers and other surface water currents. This system can be implemented in almost every location of the river and also it can be applied for a large range of river sizes. The scheme applied in this system is described as follows.The required amount of water has been separated from river using a secondary outdoor open channel (shown in Fig. 1) near the river.
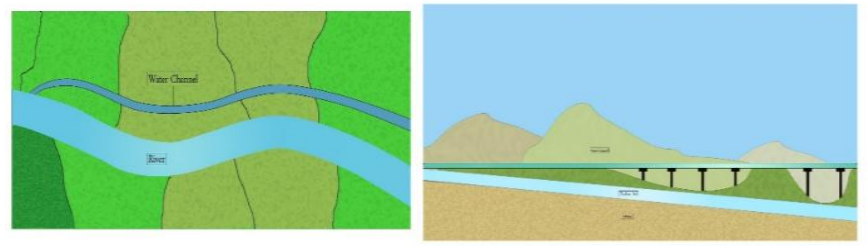

Fig. 1. Schematic view of how to extract water from the river to the channel and create head difference between the river and the mentioned channel.

As the head difference reaches to the ideal designed amount, the power generation system could be set up. In this mechanism power could be generated from the interaction between weight and buoyancy forces in the three vertical cylinders (see Fig. 2). As shown in Fig. 2 two pools are used as the capacitors in the inlet and outlet of the power generation unit.

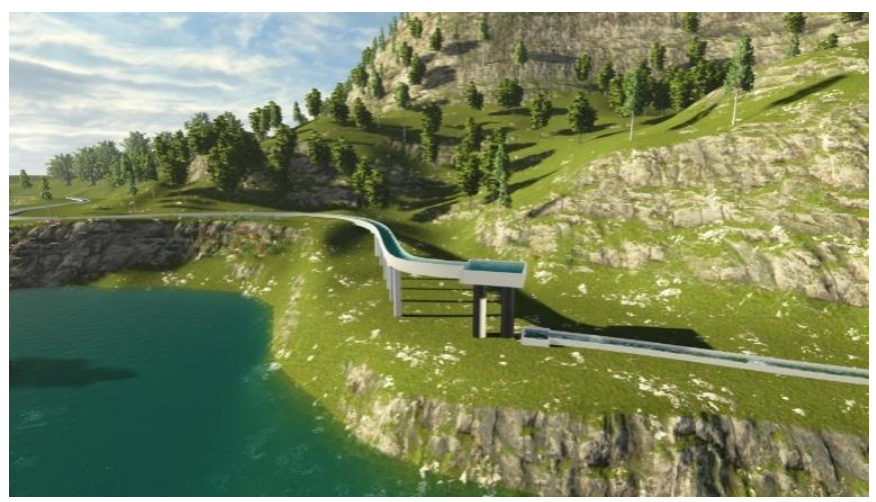

Fig. 2. The created head difference where power generation mechanism should be set up.

Fig. 3 displays details of the mentioned power plant. Three interconnected vertical canals are dug in the bed of a land near the river. Water enters first cylindrical canal (3) downwards and then flows to the other one, canal (4) through a check valve. Water pressure pushes the hollow piston in the second canal and generates power as indicated in Fig. 3. Then the first check valve closes when the piston reaches its top-most point and the downstream check valve opens immediately, as the downstream valve opens, the pressure of the water inside the second well drops so that the piston would be able to return its initial position and the water discharges from the exhaust channel (see Fig. 4).

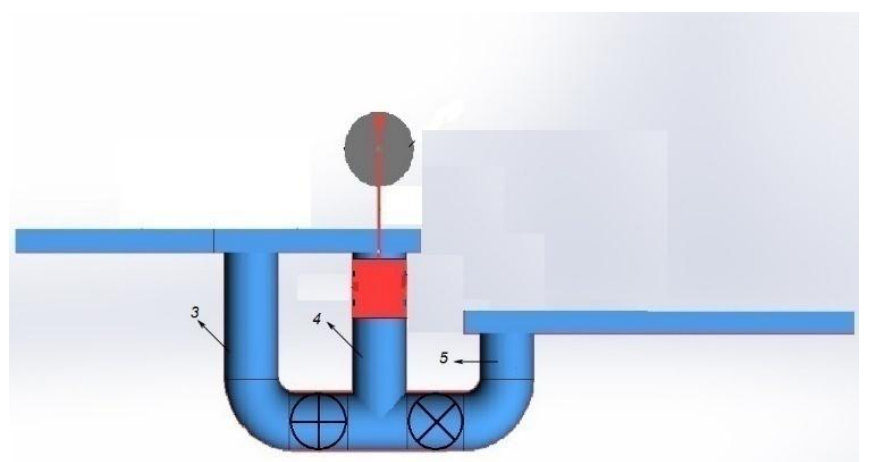

Fig. 3. First stroke of the cycle.

When piston is coming back to its bottom-most point the propulsion is its weight that is not a significant amount, so if the distance between the cylinder and piston didn't seal appropriately the buoyancy force dominates the weight of the cylinder and resist its downward movement. This problem could be solved by perfect manufacturing of the piston according to cylinder's diameter. The frictional head loss between the piston and cylinder will be calculated in the efficiency estimation part.

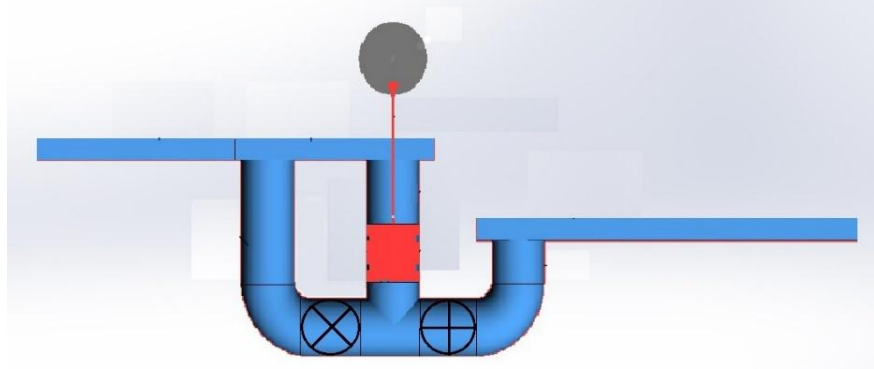

Fig. 4. Second stroke of the cycle.

This mechanism helps us to use the seas and oceans (which are near the great deserts) as the source of water too. The system could be implemented near the seas and the outlet water can be discharged in to the underground aquifers or to the sandy grounds (see Fig. 5).

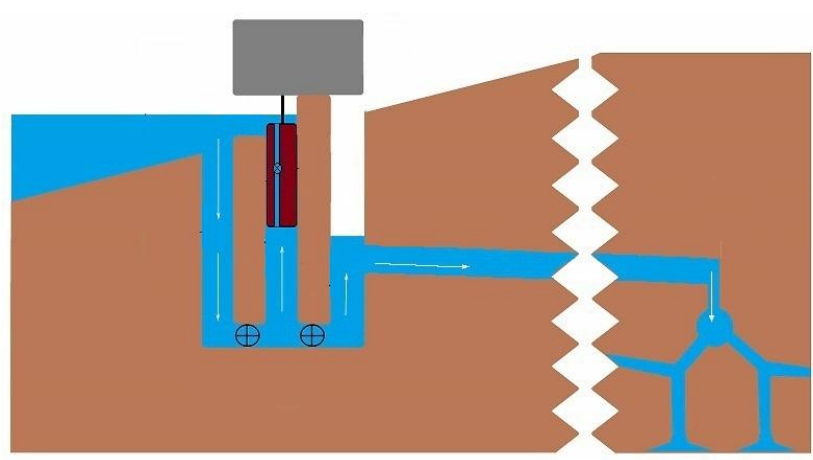

Fig. 5. Application of the mechanism for seas and oceans.

\section{HEAD LOSS COMPUTATIONS}

After introducing the details of the design, now the 
feasibility of the design must be analyzed from the efficiency point of view. Obtaining this goal we used computational fluid dynamics and also the charts of experimental works. Losses take place in three different zones. First of all the head loss happens in the open channel where extracted water transports to the power generation unit. Next the friction head loss happens into the cylinders inside the knees and tee. The friction between hollow piston and the cylinder is the final loss of this system. Hear we optimize the design of this power generation system using the presumptions mentioned in Table I.

\begin{tabular}{ccccc}
\multicolumn{5}{c}{ TABLE I: CHARACTERISTICS OF THE PROBLEM } \\
\hline $\begin{array}{c}\text { Flow Rate } \\
\left(\mathrm{m}^{3} / \mathrm{s}\right)\end{array}$ & $\begin{array}{c}\text { River Slop } \\
(\mathrm{m} / \mathrm{m})\end{array}$ & $\begin{array}{c}\text { Canal's } \\
\text { material }\end{array}$ & $\begin{array}{c}\text { Open Canal's } \\
\text { Width }(\mathrm{m})\end{array}$ & $\begin{array}{c}\text { Cylinders } \\
\text { Diameter }(\mathrm{m})\end{array}$ \\
\hline 40 & 0.004 & $\begin{array}{c}\text { Concrete } \\
\text { with rough } \\
\text { joints }\end{array}$ & 20 & 5 \\
& \multicolumn{5}{c}{} \\
\hline
\end{tabular}

With the mentioned assumptions the height of the cylinders should be near the 10 meter (to reach a head difference of 5 meter for a single of power generating systems) and the length of the open canal must be more than $1.25 \mathrm{~km}$ which are reasonable values. Calculations are done for three different open channels type (trapezoidal, rectangular, and Circular) and the needed slops for each case obtained. The results are shown in Table II.

TABLE II: HEAD LOSS IN THE DIFFERENT OPEN CHANNELS

\begin{tabular}{ccc}
\hline Type & Slope $(\mathrm{mm} / \mathrm{m})$ & Head loss percentage \% \\
\hline Trapezoid & 0.096 & 2.4 \\
rectangle & 0.137 & 3.4 \\
Circle & 2.7 & 67.5 \\
\hline
\end{tabular}

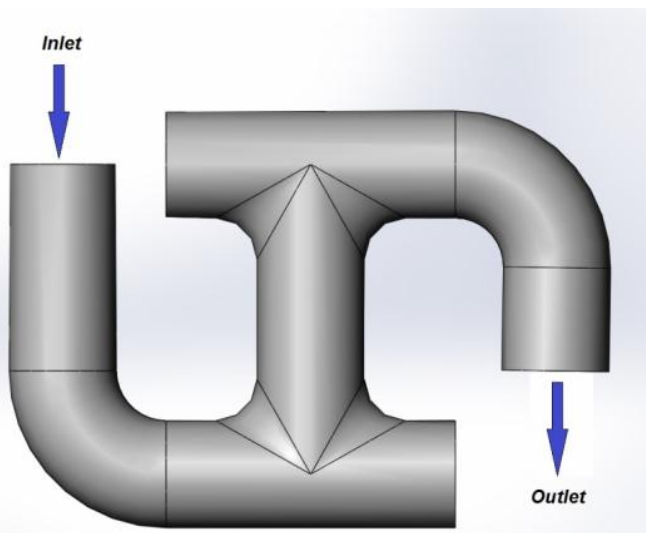

Fig. 6. The geometry for the CFD simulation.

According to the results of the Table II, channel with the trapezoidal cross section would the best selection for the first section of the open channel. In the next step the analysis of the cylinders should be done. To this end we used the flow simulation toolbox of the Solid-Works software. Turbulence model equations solved for this section. Since this system is a two-stroke power generation system (first when water pressure pushes the piston upward and the second for discharging water), to simplify the process we replace a conjoined geometry as shown in Fig. 6. This estimation might be neglect some of the features of the fluid flow but it is an acceptable estimation for the conceptual design of the system which is analyzed hear in this work. Since the amount of frictional head loss with a specified flow rate is the target of this calculation, the gravity effects could be neglected.

Flow streamlines and also pressure distribution is shown in Fig. 7. According to the flow specifications $18 \mathrm{~cm}$ head loss calculated between inlet and outlet of the power generating system; therefore there is an about 3.6 percent head loss in this part.

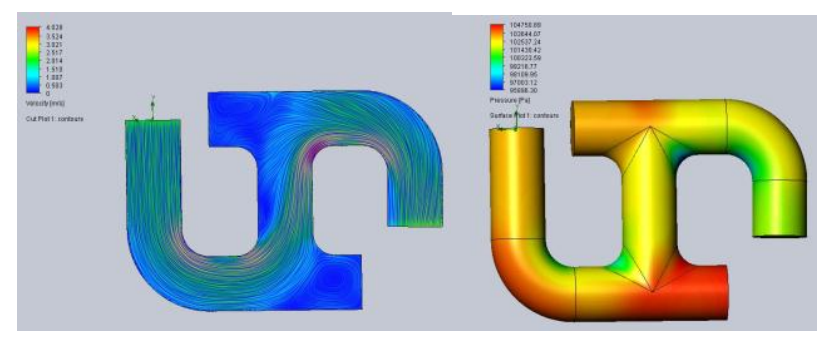

Fig. 7. Velocity and pressure distribution.

The information about pressure is displayed in Table III.

TABLE III: INFORMATION ABOUT PRESSURE

\begin{tabular}{cc} 
Inlet mean pressure & $105126.88 \mathrm{pa}$ \\
Outlet mean pressure & $103397.5 \mathrm{pa}$ \\
Pressure drop & $1729.4 \mathrm{pa}$ \\
Head loss & $0.18 \mathrm{~m}$ \\
\hline
\end{tabular}

Final step in efficiency estimation of the design is to determine the frictional losses between piston and the cylinder. To this end, a small gap of about $3 \mathrm{~cm}$ thickness desired between the cylinder and piston and the Navier Stokes (NS) equations solved for in the axial direction (see Fig. 8). A parabolic velocity profile obtained which utilized calculating of the shear stress for the hollow piston. Using shear stress and the velocity of the piston leads a $5.5 \mathrm{~cm}$ head loss (about 1.1 percent) of the power plant.

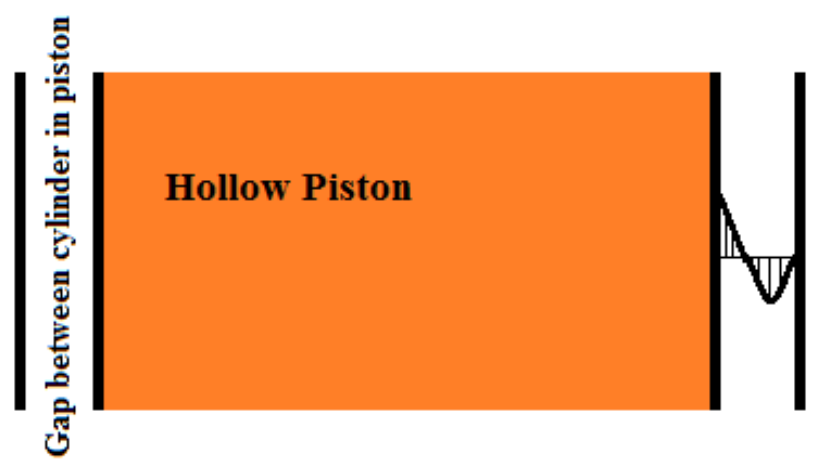

Fig. 8. Schematic view of the velocity profile inside the gap between cylinder and piston.

TABLE IV: PluRALIZATION OF THE HEAD LOSSES IN THE WHOLE SySTEM

\begin{tabular}{ccccc} 
Case of study & $\begin{array}{c}\text { Open } \\
\text { channels }\end{array}$ & Cylinders & $\begin{array}{c}\text { Cylinder-Piston } \\
\text { friction }\end{array}$ & total \\
\hline $\begin{array}{c}\text { Head loss } \\
\text { percentage }\end{array}$ & 2.4 & 3.6 & 1.1 & 7.1 \\
\hline
\end{tabular}

\section{CONCLUSION}

As shown in Table IV, it could be concluded the total head loss is less than 10 percent which means that more than 90 percent of the water head converts to useful mechanical power (and could be improved using the improved fabrication technologies). Indeed this simulation reveals that the new power generation system has the capabilities of competition 
with the classical hydropower power plants.

The present design have some great advantages compared to the turbines, first of all it could be applicable in the regions where the water head is not significant but turbines are efficient for heads more than 50 meter most of the times. Also this system could be applied for the region where construction of the dams is not possible.

\section{REFERENCES}

[1] H. S. Alavije, A. Kiyoumarsioskouei, M. H. Asheri, H. S. Alavije, and H. B. Tabrizi, "Greenhouse gas emission measurement and economic analysis of Iran natural gas fired power plants," Energy Policy, vol. 60, no. 9, pp. 200-207, September 2013.

[2] H. S. Alavije, A. Kiyoumarsioskouei, H. S. Alavije, and M. H. Asheri, "Experimental analysis of $\mathrm{CO}_{2}, \mathrm{CO}, \mathrm{SO}_{2}$ and $\mathrm{NO}_{\mathrm{x}}$ emission factors of Iran's fossil fuel fired power plants," in Proc. 2010 IEEE International Energy Conf., 2010, pp. 775-779.

[3] T. B. Johansson and L. Burnham, Renewable Energy: Sources for Fuels and Electricity, 1993.

[4] G. W. Frey and D. M. Linke, "Hydropower as a renewable and sustainable energy resource meeting global energy challenges in a reasonable way," Energy Policy, vol 30, issue 14, pp. 1261-1265, November 2002.

[5] B. R. Munson, D. F. Young, and T. H. Okiishi, Fundamentals of Fluid Mechanics, 4th Edition, John Wiley \& Sons, 2010.

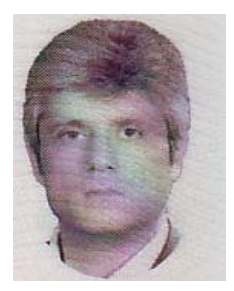

A. Shokuhi was born in Amol, Iran. He started his education in field of law but as he was intensely interested in energy researches, he started to establish a research center in Tehran working on renewable energies.

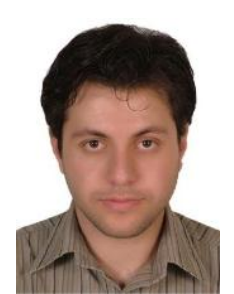

A. Kiyoumarsioskouei was born in Osku, Iran. He started his education in mechanical engineering in Amir Kabir University of Technology (Tehran Polytechnic) in 2003. Now he is working in the research center as a researcher. 